\title{
The impact of taxes and administrative activities of SMEs on their performance
}

\author{
Stanislav Bilek ${ }^{1, *}$, Iveta Kmecova ${ }^{1}$, and Michal Tlusty ${ }^{2}$ \\ ${ }^{1}$ Institute of Technology \& Business in Ceske Budejovice, Faculty of Corporate Strategy, Department \\ of Human Resource Management, Okruzni 517/10, Ceske Budejovice 37001, Czech Republic \\ ${ }^{3}$ Institute of Technology \& Business in Ceske Budejovice, Okruzni 517/10, Ceske Budejovice 37001, \\ Czech Republic
}

\begin{abstract}
.
Research background: The paper outlines selected problem areas of the legislative - legal environment and administrative burdens for SMEs. Data for this paper were obtained within the scientific activities at the University of Technology and Business in Ceske Budejovice Project TL01000349 Stabilization and development of SMEs in rural areas. The primary objective of the paper is to demonstrate that small and medium-sized enterprises are overburdened both from an administrative point of view. The theoretical part of the paper is devoted to the presentation of experts on a given topic and from these views the logical conclusion and recommendations for the methodological part of the paper are based. The following, practical part, explains each hypothesis and outlines the whole course of calculation. Each hypothesis is then rejected or confirmed. All findings are verbally analysed in the discussion of the results.

Purpose of the article: The main purpose of the research is to prove that small and medium-sized enterprises are overburdened with administrative burdens and taxes.

Methods: Primary data for the area of legislative-legal and administrative burden were obtained through a questionnaire survey in SMEs. The data will be evaluated using a statistical method comparing the mean value, specifically using a one-sample t-test.

Findings \& Value added: The results of the paper will confirm or reject the predetermined hypotheses that apply to small and medium-sized enterprises. This knowledge will be important for further analysis and will outline the administrative complexity of the business of these companies.
\end{abstract}

Keywords: legislative-legal environment; administrative burden; administrative complexity; small and medium enterprises; statistical onesample t-test

JEL Classification: $M 12$

*Corresponding author: bilek@mail.vstecb.cz 


\section{Introduction}

The issue of legislative and legal basis of small and medium-sized enterprises and the related administration attracts the attention of many experts. Legislative and legal basis, as well as the administrative burden for enterprises was significantly affected by the entry of the Czech Republic in the European Union on 1 May 2004 [1]. Small and medium-sized enterprises constitute a majority of enterprises in the CR; the main obstacles to their development thus needs to be analysed. The obstacles definitely include legislative and business environment as well as the societal relations $[2,3]$.

The contribution is focused on the identification of the main obstacles in this area from the perspective of the SMEs on the bases of the data obtained from the following sections: Administrative burden - Tax burden, Social and Health insurance, and the complexity of specific requirements, such as Standards, Norms, Directives.

Balanced administrative tasks for small and medium-sized enterprises, such as tax burden, complexity of social and health insurance, complexity of some standards, norms, directives, or requirements for specific technologies are very important for enterprises; the inability of enterprises to cope with these requirements may cause big problems. A study examining the basic purpose of taxes has been elaborated, whose authors claim that taxes are considered to be the main mechanism of financing government expenditures $[4,5]$. Further research examined whether setting appropriate taxes could be a stimulus to innovate for enterprises. A hypothesis was formulated, according to which income taxes affect corporate work on innovations. The results of the research confirmed that income taxes do affect the innovative activity of enterprises, especially those with weak management, fewer assets, stronger financial limitations, and lower patent stocks [6]. Another study dealing with this topic was conducted between 1980-2016, where there was economic growth in India. The authors concluded that both the tax structure and mainly the economic growth strongly affect the tax and administrative burden laid on enterprises in India. Enterprises showing economic growth and subject to changing tax burden find tax burden less difficult to handle $[7,8,9]$. The question of whether an enterprise's ability to pay tax is affected by the amount of corporate income was addressed by a hypothesis claiming that tax burden is more demanding with a higher income. The authors concluded that tax burden is more burdensome for an enterprise or entrepreneur with a higher income; the hypothesis was thus confirmed [10]. In Germany, research was conducted to examine the relationship between tax burden and income, more specifically, the adequacy of the tax system. It has been found that the adequacy of the tax system is primarily dependent on the reactions of taxpayers. Other results indicate that low income is associated with the delays in rendering tax return compared to the persons / households with higher income. It is possible that tax burden for an enterprise could be influenced by the access to the internet [11]. This issue was addressed in a study dealing with the question whether the access to the internet influences the tax burden of enterprises in developing countries. It was found that the tax burden on enterprises in developing countries is easier to handle when having an access to the internet and information. Another advantage was a possibility to present themselves on the internet and to inform about changes or news [12]. The latest research was trying to find out whether the current crisis associated with COVID-19 may have effect on the tax burden for enterprises. The research results indicate that although the situation with COVID-19 seems to be of nonrecurring character and neither enterprises nor states were prepared for it, in terms of business sector, most states were able to react and reduce the consequences of this crisis [13]. Research focused on standards and norms provided an opportunity to have an overview of the structure of standards and norms enterprises have to deal with, and analysed whether the structure has an effect on the administrative burden laid on enterprises. The study showed that there is a certain effect, although not large, and has to be taken into account. It was also proved that 
when the structure of norms and standards changes significantly, the enterprises are exposed to great pressure to adapt to the requirements [14]. Another hypothesis was formulated, claiming that the necessity to observe standards, norms, directives, and to comply with the principles of social responsibility and sustainable development represents a great burden for the corporate structure of manufacturing enterprises in Japan. The hypothesis was confirmed, with a comment that although the enterprises are exposed to great pressure, it is necessary for them to adapt to the situation and focus their management on this direction, since the pollution of the planet would have fatal consequences in the future, and it is necessary and change the world so that this would not happen [15].

It is important that the complexity of taxes, directives, and similar requirements laid on enterprises, especially the smaller ones, was balanced. Otherwise, such elements represent a great burden for the enterprises, thus affecting their productivity. With the existence of modern large corporations, states strive for retaining small enterprises by adopting various measures that could help these small enterprises with their business activities. However, small enterprises still have problems to handle the competition and need even more help, which could be in the form of tax relief or reduction of specific directives and requirements. regulations. Tax structure and other requirements need to be analysed in detail to identify the importance of the problems and how difficult it is for small and medium-sized enterprises to cope with them. Then it will be possible to tackle the problems and adopt relevant measures.

\section{Methodology and Data}

The primary goal of the article is to use a statistical method, specifically a one-sample t-test, to confirm or reject hypotheses concerning the administrative complexity of SME business.

\subsection{The methods of data collection}

The study is based on a questionnaire survey. Primary data for the area of legislative-legal and administrative burden were obtained through a questionnaire survey in SMEs. It was an online questionnaire: Legislative-legal and administrative complexity of business. The questionnaire was created using the tool: Google Apps - Questionnaires. The questionnaire was administered during 2019. The return rate of the questionnaires was $35 \%$ (out of 500 SMEs). There was a total of 175 completed questionnaires.

The research set of companies was divided according to the set criteria. The companies were divided according to the sector in which they operate. The first group included enterprises operating in the primary and secondary sectors, due to the fact that these sectors are similar and the number of enterprises in these groups was not very high. The second group included companies operating in the tertiary sector.

\subsection{The methods of data assessment}

For the analysis of administrative demands (taxes, social and health insurance, directives, standards, norms), the statistical method of one-sample t-test was chosen, which compares the mean values of selected samples. The final value of the one-sample t-test was confirmed using the p-value and $95 \%$ quartile for this calculation, it is necessary to calculate the relevant quantities, namely the arithmetic mean, the sampling variance, the standard and standard deviation. When these quantities are known, it is possible to calculate a specific t-test value. Furthermore, it is necessary to establish null hypotheses and relevant alternative hypotheses. The $95 \%$ confidence interval was chosen for this post [16]. 
Where:

$$
t=\frac{\bar{x}-\mu_{0}}{\sigma} \sqrt{n}
$$

$t=$ value of one-sample t-test

$\bar{x}=$ arithmetic mean

$\mu_{0}=$ established null hypothesis

$\sigma=$ standard deviation

$n=$ number of sample values

Finally, it is likely that the resulting t-test values with critical values that can be obtained from the available table. This table is available on the Internet. If the resulting value of the ttest in absolute value is lower than the critical value from the tables, the hypothesis can be confirmed. Otherwise, if the calculated value of the t-test in absolute value is higher than the value from the tables, the hypothesis can be rejected $[17,18]$.

\section{Results}

Null hypothesis: Enterprises in the primary and secondary sectors consider the tax intensity of business (income tax, value added tax, excise duty) demanding by $60 \%$ (2.4 points). Enterprises operating in the tertiary sector consider the tax intensity of business (income tax, value added tax, excise duty) to be 60\% (2.4 points) (comparison)

Enterprises answered on a point scale of 1-4, where a value of 1 means a complexity of about $25 \%$ and a value of 4 indicates a complexity of $100 \%$. In the first case, it is necessary to calculate the arithmetic mean of both samples. There was a total of 71 enterprises operating in the primary and secondary sectors and the sum of the values of their answers was 183.33.

$$
\begin{gathered}
t_{1}=\frac{2.58-2.4}{0.74} \sqrt{71}=2.05 \\
t_{2}=\frac{2.63-2.4}{0.79} \sqrt{94}=2.82 \\
\text { Critical value }_{1}=-1.994 ; 1.994 \\
\text { Critical value }_{2}=-1.1987 ; 1.987
\end{gathered}
$$

It is obvious that both final values of t-tests are higher than the respective critical values and thus the whole hypothesis can be rejected. Subsequently, these statements can be confirmed using p-values obtained using R Commander statistical software.

$$
\begin{gathered}
p-\text { value }_{1}=0.04302=4.3 \% \\
p-\text { value }_{2}=0.01334=1.33 \%
\end{gathered}
$$

As the tests are performed at a significance level of $95 \%$, it is necessary to compare the values with the value of 5\%. The first $\mathrm{p}$-value is less than $5 \%$ and so it is proved that the decision to reject this part of the hypothesis was correct. The second $p$-value is less than $5 \%$, so even in this case it is possible to confirm that the second part of the hypothesis was rejected correctly. These statements are proved by $95 \%$ of the sample quartile. The $95 \%$ quartile for the first selection is 2.41 to 2.76 and for the second selection is 2.44 to 2.78 . The value of the null hypothesis 2.4 is not in any of these quartiles, so this method also confirmed the correctness of the decision to reject the hypotheses.

Null hypothesis: Enterprises in the primary and secondary sectors consider the complexity of social and health insurance to be 60\% demanding (2.4 points). Enterprises operating in the tertiary sector consider the complexity of social and health insurance to be $60 \%$ (2.4 points) demanding (comparison).

$$
\begin{aligned}
& t_{1}=\frac{2.64-2.4}{0.71} \sqrt{71}=2.85 \\
& t_{2}=\frac{2.56-2.4}{0.81} \sqrt{94}=1.92
\end{aligned}
$$


Critical value $_{1}=-1.994 ; 1.994$

Critical value $_{2}=-1.987 ; 1.987$

The first value of the t-test is higher than the critical value and this part of the hypothesis can therefore be rejected. The second value of the t-test is smaller than the corresponding critical value and so this part of the hypothesis can be confirmed.

$$
\begin{gathered}
p-\text { value }_{1}=0.005803=0.5 \% \\
p-\text { value }_{2}=0.05497=5.5 \%
\end{gathered}
$$

It is obvious that the first $p$-value is less than $5 \%$ and thus the rejection of the first part of the hypothesis is confirmed. The second p-value is higher than $5 \%$ and so even in this case the correct decision is confirmed, namely to confirm this part of the hypothesis. Finally, both decisions can be confirmed by a $95 \%$ quartile. The corresponding quartile for the first part of the hypothesis is 2.47 to 2.81 and it is therefore clear that the value of 2.4 is not in this quartile. The quartile for the second part of the hypothesis is 2.39 to 2.73 and the value of 2.4 is in this range.

Null hypothesis: Companies in the primary and secondary sectors consider the complexity of standards, norms, directives and requirements for specific technologies to be $60 \%$ demanding (2.4 points). Enterprises operating in the tertiary sector consider the complexity of standards, norms, directives and requirements for specific technologies to be $60 \%$ demanding (2.4 points) (comparison).

$$
\begin{gathered}
t_{1}=\frac{2.7-2.4}{0.63} \sqrt{71}=4.01 \\
t_{2}=\frac{2.68-2.4}{0.7} \sqrt{94}=3.88 \\
\text { Critical value }_{1}=-1.994 ; 1.994 \\
\text { Critical value }_{2}=-1.987 ; 1.987
\end{gathered}
$$

As can be seen from the results, both values of the t-tests are larger than the respective critical values and thus the whole hypothesis can be rejected.

$$
\begin{aligned}
& p-\text { value }_{1}=0.0001345=0.01 \% \\
& p-\text { value }_{2}=0.0002098=0.02 \%
\end{aligned}
$$

Both p-values are clearly lower than the limit of 5\% and so the hypothesis can be rejected in this way as well. The last confirmation is $95 \%$ quartiles. The corresponding quartile for the first selection is 2.56 to 2.85 . The value of 2.4 is not in this range and so the first part of the hypothesis is rejected in this way as well. The quartile responsible for the second selection is 2.54 to 2.83 and the value of 2.4 is also not in this range. The whole hypothesis was therefore rejected and it was found that the surveyed companies consider the complexity of standards, norms, directives and requirements for specific technologies to be much more demanding than $60 \%$.

\section{Discussion and Conclussion}

All statements based on the article are clearly shown in table number 1 .

Table 1. Summary of the resulting claims.

\begin{tabular}{|c|c|c|c|}
\hline Hypothesis & T-test values & Critical values & Result \\
\hline $\mathrm{H}_{1}$ & $2.05 ; 2.82$ & $\begin{array}{r}-1.994 \text { and } 1.994 ; \\
-1.987 \text { and } 1.987\end{array}$ & Hypothesis rejected \\
\hline $\mathrm{H}_{2}$ & $2.85 ; 1.92$ & $\begin{array}{l}-1.994 \text { and } 1.994 ; \\
-1.987 \text { and } 1.987\end{array}$ & $\begin{array}{c}\text { The first part rejected; } \\
\text { the second part } \\
\text { confirmed }\end{array}$ \\
\hline $\mathrm{H}_{3}$ & $4.01 ; 3.88$ & $\begin{array}{l}-1.994 \text { and } 1.994 ; \\
-1.987 \text { and } 1.987\end{array}$ & Hypothesis rejected \\
\hline
\end{tabular}


Null hypothesis: Enterprises in the primary and secondary sectors consider the tax intensity of business (income tax, value added tax, excise duty) demanding by 60\% (2.4 points). Enterprises operating in the tertiary sector consider the tax intensity of business (income tax, value added tax, excise duty) to be 60\% (2.4 points) (comparison).

The first hypothesis examined whether the difference in how companies are divided according to the sectors in which they operate perceives the tax intensity of business. Specifically, these were income tax, value added tax and excise duty. It was found that both companies in the primary and secondary sectors and companies in the tertiary sector do not consider $60 \%$ tax burden, but consider it to be more demanding. This hypothesis was therefore rejected.

Null hypothesis: Enterprises in the primary and secondary sectors consider the complexity of social and health insurance to be 60\% demanding (2.4 points). Enterprises operating in the tertiary sector consider the complexity of social and health insurance to be $60 \%$ (2.4 points) demanding (comparison).

The kind of hypothesis dealt with the complexity of social and health insurance for businesses. It was found that social and health insurance for companies in the primary and secondary sector is not $60 \%$, but more demanding. On the other hand, companies in the tertiary sector consider the severity of social and health insurance to be $60 \%$, and this hypothesis has therefore been confirmed. Thus, it was found that social and health insurance does not pose such problems for enterprises in the tertiary sector as it does for enterprises operating in the primary and secondary sectors.

Null hypothesis: Companies in the primary and secondary sectors consider the complexity of standards, norms, directives and requirements for specific technologies to be $60 \%$ demanding (2.4 points). Enterprises operating in the tertiary sector consider the complexity of standards, norms, directives and requirements for specific technologies to be $60 \%$ demanding (2.4 points) (comparison).

The last hypothesis concerned the complexity of standards, norms, directives and requirements for specific technologies. In this case, it was found that both companies in the primary and secondary sectors and companies in the tertiary sector do not consider these aspects to be $60 \%$ demanding, but much more so. Overall, it can be argued that companies consider standards, norms, directives and requirements for specific technologies to be very demanding and thus a major obstacle in their business.

In the conclusion, it could be summarized that the enterprises classified by sector in which they operate were subject to statistical analysis, more specifically, statistic t-test and other additional calculations related to the above. Hypotheses were formulated, which were rejected or confirmed based on the results of one-sample t-test and a table of critical values. The sample included a total of 165 small and medium-sized enterprises, from which 71 enterprises operated in primary and secondary sector, and 94 enterprises in the tertiary sector. The hypotheses concerned the entrepreneurship tax burden, social and health insurance, and the complexity of standards, norms, directives, and requirements for specific technologies. The resulting confirmation or rejection of hypotheses was extended by the comparison of $\mathrm{p}$ values and $95 \%$ quartile, which confirmed the correctness of the decision.

The first hypothesis, presenting the opinion that $60 \%$ small and medium-sized enterprises consider tax burden difficult to handle was rejected, as it was found that the values are higher than expected. The second hypothesis, claiming that $60 \%$ of enterprises consider social and health insurance difficult to handle, was only partially rejected. More specifically, there are more than $60 \%$ of enterprises operating in the primary and secondary sector that consider the tax burden difficult to handle, compared to $60 \%$ of enterprises operating in the tertiary sector. The last hypothesis that analysed the complexity of entrepreneurship in terms of standards, norms, directives, and requirements for specific technologies was rejected, as it 
was found that they represent a big problem for more than $60 \%$ of the enterprises (almost 70 $\%$ more precisely).

\section{References}

1. Kmecová, I., Bílek, S. (2020). Legislativně-právní základna a administrativní zátěž MSP. Malé a střední podnikání v České republice - současnost a vize. Praha: Grada Publishing.

2. Korcsmáros, E., Šimova, M. (2017). The Main Barriers to the Development of SMEs. In I. Košičiarová \& Z. Kádeková (Eds.), Proceedings of the 7th International Scientific Conference on Managerial Trends in the Development of Enterprises in Globalization Era (pp. 146-152). Nitra: Slovak University of Agriculture.

3. Caha, Z., Urban, J. (2020). Human Resource Management in SMEs in the Czech Republic - Specifics and Key Requirements. SHS Web of Conferences, 73, 02001.

4. Baker, A., Murphy, R. (2020). Modern Monetary Theory and the Changing Role of Tax in Society. Social Policy and Society, 19(3), 454-469.

5. Lan, F., Wang, W., Cao, Q. (2020). Tax cuts and enterprises' R\&D intensity: Evidence from a natural experiment in China. Economic Modelling, 89, 304-314.

6. Atanassov, J., Liu, X. (2020). Can Corporate Income Tax Cuts Stimulate Innovation? Journal of Financial and Quantitative Analysis, 55(5), 1415-1465.

7. Ližbetinová, L., Hitka, M. (2017). Selection of Most Suitable Candidates for the Talent Pool in a Furniture Manufacturing Company. Drvna Industrija, 67, 333-340.

8. Neog, Y., Gaur, A. K. (2020). Tax structure and economic growth in India: insights from ARDL model. Indian Growth and Development Review, forthcoming article.

9. Abo-Zaid, S. (2020). Taxation, credit frictions and the cyclical behavior of the labor wedge. Empirical Economics, forthcoming article.

10. Rubolino, E., Waldenström, D. (2020). Tax progressivity and top incomes evidence from tax reforms. The Journal of Economic Inequality, 18(3), 261-289.

11. Schächtele, S. (2020). Tax Responses at Low Taxable Incomes: Evidence from Germany. Fiscal Studies, 41(2), 411-439.

12. Gnangnon, S. K. (2020). Internet and tax reform in developing countries. Information Economics and Policy, 51, 100850.

13. Karnon, J. (2020). The Case for a Temporary COVID-19 Income Tax Levy Now, During the Crisis. Applied Health Economics and Health Policy, 18(3), 335-337.

14. Senn, J., Giordano-Spring, S. (2020). The limits of environmental accounting disclosure: enforcement of regulations, standards and interpretative strategies. Accounting, Auditing \& Accountability Journal, 33(6), 1367-1393.

15. Goto, M., Sueyoshi, T. (2020). Sustainable development and corporate social responsibility in Japanese manufacturing companies. Sustainable Development, 28(4), 844-856.

16. Budíková, M. (2010). Průvodce základními statistickými metodami [Guide to basic statistical methods]. Praha: Grada.

17. Dalgaard, P. (2009). Introductory Statistics with R. New York: Springer.

18. Sedlačík, M., Neubaeur, J., Kříž, O. (2016). Základy statistiky - Aplikace $v$ technických a ekonomických oborech [Basics of statistics - Applications in technical and economic fields]. Praha: Grada. 